nonverbal signals and fleeting glimpses of emotion - telling clues that they can then follow up on. "That expression lets the patient know not only that you've understood what they've said, but you have understood on a deeper level," Haidet says.

He notes that many doctors working at inner-city public hospitals learn to achieve a level of connection and understanding in a short time.

Box 1: Suggested listening

- Now's the Time, Sonny Stitt (alto saxophone) from Stitt Plays Bird (Atlantic/Warner)

- All Blues, Miles Davis (trumpet) from Kind of Blue (Sony/BMG)

- Giant Steps, John Coltrane (tenor saxophone) from Giant Steps (Atlantic/Warner)

- Waltz For Debby, Bill Evans (piano), Scott LaFaro (bass) from The Best of Bill Evans (Fantasy Inc.)
"They're very good at getting centred and being in the moment with those patients," he says. "They listen deeply and co-construct the narrative with the patient."

It's not a one-way street. Haidet also

\section{Box 2: Clinical exercises}

1. "Mastering space"

For the next two weeks, pick one time when the patient is finishing a sentence. Wait for at least 10 seconds before saying anything. If the patient talks before 10 seconds, follow up on what they say. Watch for the times when the patient says something unexpected or profound.

2. "Cultivating ensemble"

For the next two weeks, say a sentence that begins with: "So, what I'm hearing you say is... " Do this once with every patient. After two weeks, do it when it feels right. Experiment with different ways of saying the phrase. notes that patients need to be assertive - and studies support that theory. In many cases, "interventions were associated with improved physician and patient communication behaviors." 3

In reviews of Haidet's course, doctors remarked that while most of what they learned wasn't new to them, the material allowed them to enjoy their practice much more.

\section{Fateema Sayani BJ}

Music critic

Ottawa, Ont.

\section{REFERENCES}

1. Haidet P. Jazz and the 'art' of medicine: improvisation in the medical encounter. Ann Fam Med 2007;5:164-9.

2. Beckman HB, Frankel RM. The effect of physician behavior on the collection of data. Ann Intern Med 1984:101:692-6.

3. Rao JK, Anderson LA, Inui TS, et al. Communications interventions make a difference in conversations between physicians and patients: a systematic review of the evidence. Med Care 2007;45:340-9.

\title{
A commentary on the truth
}

Previously published at www.cmaj.ca

The orange wire problem and other tales from the doctor's office

David Watts

University of lowa Press; 2009.

186 pp $\$ 25.00$

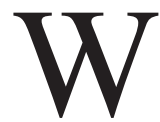
riting reflective essays about clinical experiences is a complex endeavour that can appear deceptively simple.

It is not always easy to balance fidelity to the facts with the imperative to maintain patient confidentiality. There are the ethical questions of what benefits are accrued, and to whom, and what the risks might be. There is the matter of choosing your audience and deciding how best to speak to them.

The number of physicians who write despite these difficulties is quite striking and while not everyone possesses

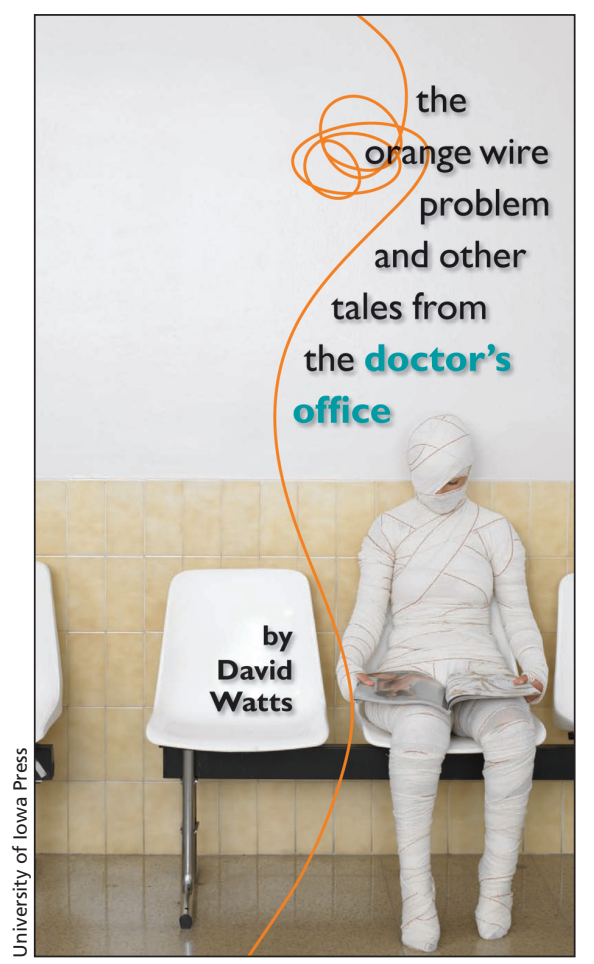

the same degree of skill, there is generally an earnest quality to the writing that suggests an effort to understand, and to share, truth.

San Francisco, California, physician David Watts takes this task seriously. As well as authoring several books on medicine, he is a poet, musician, and television personality. In the preface to The orange wire problem and other tales from the doctor's office he writes that he is striving "not so much to document as to approach a truth that goes beyond nonfiction and dares to flirt with the realm of mystery." As such a statement would suggest, this is an ambitious book.

In 26 short narratives, Watts provides sparse sketches of encounters between doctor and patient. Most of the clinical scenarios will be familiar to physicians, but Watts imbues them with importance and significance. He brings himself deeply into the encounters and 
does not back away from sharing his own emotions, whether he is dealing with a patient's insurance company or talking to the physician caring for his own dying mother.

Description is kept to a minimum. Dialogue flows without quotation marks. At times this makes it difficult to tell whether words are spoken by the patient or the doctor, and the line between communication and internal reflection is indistinct. It's a style of writing that differs from the norm among books written by doctors: It keeps the reader slightly off-balance and compels attention. Yet the book itself is easy to read and not without humour, despite its lofty ambitions.

There is a line in the book where Watts tells one of his patients: "A doctor is supposed to share not just truth but wisdom, which, if you will, is a commentary on the truth." This goal can apply not only to clinical situations, but also to the process of writing creatively.
Bravery is one of the virtues we don't often talk about in medicine, but it takes a special sort of courage to be present with a patient's pain, to hold the experience long enough to examine it and then to bare one's soul in the commentary on the truth.

This is a book that aspires to be not only brave, but wise.

\section{Lara Hazelton MD \\ Psychiatrist \\ Halifax, NS}

\section{Creative WORKS}

\section{Forms of waiting}

$\mathrm{T}$

hirty years ago, in my second year psychiatry, I suffered dread during on-call at Douglas Hospital. The hospital, set on 170 acres between Montréal's Lachine Canal and the St. Lawrence River, had more than 1000 mental-health patients. I was the sole on-call, responsible for everything: medical crises, dressing and suturing wounds, monitoring infections, drug reactions and attempting to sedate violent and suicidal patients. If I didn't know what do, I read manuals, spoke to nurses, called the staff psychiatrist and waited for the patient to get better - or worse.

On this particular on-call evening, the hospital was marooned by a violent blizzard. Lights flickered, broadcasts warned of whiteouts, falling power lines, school closures and airplane delays. Outside, the maelstrom roared and trees snapped; inside, the hospital was still and my beeper mute. By 11:30, the evening nurses were asleep in spare ward beds; night staff who were unable to reach the hospital remained housebound. Unable to sleep, I threw on my boots and coat and trudged knee deep in snow as the savage sky whitewashed the earth. When I returned to my room, I crept into bed, sniffed my clean sheets and sank into a deep sleep.

An hour later, the irate head nurse phoned. A patient, sleepless for more than two days, threatened to leave. Where

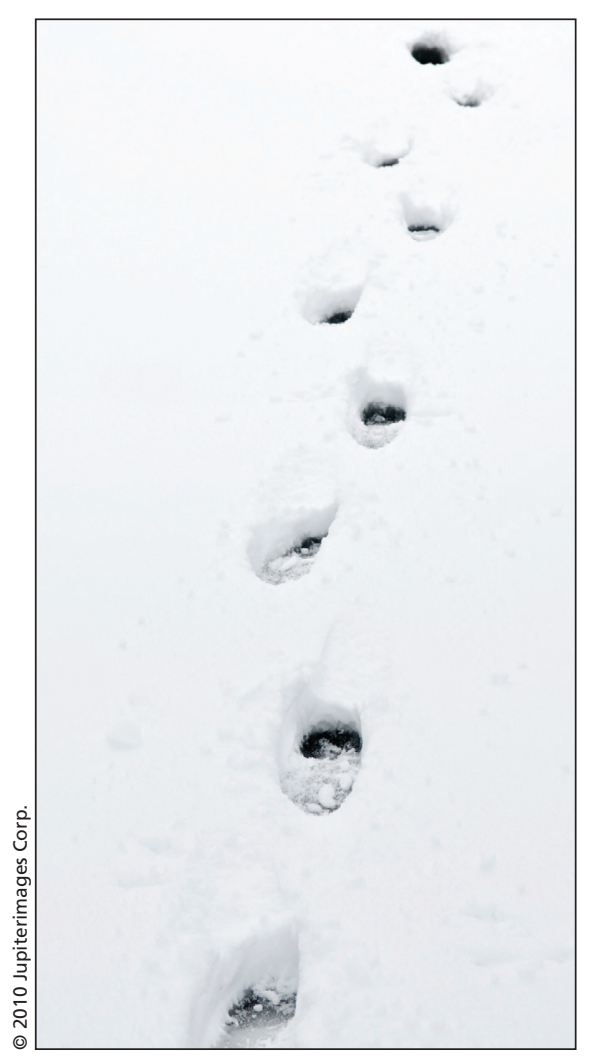

was I? My beeper was dead. Hurriedly I dressed and marched through a sombre underground tunnel to a locked ward and was informed about Sophie. I reviewed her chart, met with the head nurse and checked my psychiatric manual.

Sophie was on lithium, valium and thousands of milligrams of chlorpromazine. Nothing touched her. "Watch out," the head nurse warned. "She's sly, foxy."

"Finally, a nice doctor," a comely blonde in a hospital gown greeted us with a Lauren Bacall voice. "Silly nurse," she grinned. "Doctor, you'll send me home now?"

"I would like to talk to you."

"You can take me home."

Sophie spoke dry-mouthed and rapidly. Her eyes sparkled like icicles.

"The staff are worried you haven't slept."

"I sleep when no one is looking," she winked. "You can sleep with me."

After a fruitless talk with Sophie, the nurse and I walked into the hall. "Put her in a quiet room," she advised. Feeling cruel, but knowing the nurse was correct, I explained the move to Sophie.

"Get out!" she cried. She hurled insults. She kicked the door. "I don't trust you!"

"Sophie hasn't taken liquids for over a day - she's too hyper," the nurse said.

We returned with a cup of ginger ale. Sophie flung it at us. As we left I heard her ranting tearfully, pounding the walls. "She's getting more manic," the nurse said.

I found a new copy of Freedman \& Kaplan (1975) on the ward and reviewed drug treatment. There were not many options. "Now what do I do?"

"Sedation," the head nurse said. I waited a half-hour during which time 